\title{
Poly(lactic acid)/Natural Rubber Blends
}

\author{
Sándor Hajba ${ }^{1, a^{*}}$, Tamás Tábi1,2, b \\ ${ }^{1}$ Department of Polymer Enginering, Faculty of Mechanical Engineering Budapest University of \\ Technology and Economics, Müegyetem rkp. 3, 1111 Budapest, Hungary \\ ${ }^{2}$ MTA-BME Research Group for Composite Science and Technology, Müegyetem rkp.3, \\ 1111 Budapest, Hungary \\ ahajba@pt.bme.hu, btabi@pt.bme.hu,
}

Keywords: biopolymers, polymer blends, poly(lactic acid), natural rubber, biodegradable polymers

\begin{abstract}
Nowadays biopolymers are in the focus of many research and Poly(lactic acid) (PLA) is the one of the candidates of this field. The rigid behavior of PLA limits its application field, thus it is mostly used for rigid packing. Our research aim is to increase PLA ductility while keeping the biodegradability as much as possible. In our study, PLA was melt mixed in an internal mixer with 5, 10,20 and $30 \mathrm{wt} \%$ natural rubber. It was possible to increase the toughness to a three time higher value compared to neat PLA while the tensile and flexural properties only decreased maximum $30 \%$.
\end{abstract}

\section{Introduction}

Nowadays, the renewable resource-based biopolymers are gaining more and more attention. These biopolymers could provide adequate alternatives to petroleum based polymers in the future. The most prominent representative of this group is the Poly(lactic acid) (PLA), which has good mechanical, optical properties and UV resistance. It could be processed with the conventional thermoplastics technologies. However, the main disadvantage is the rigid behavior of PLA. To increase the toughness of PLA there are several possibilities. One of them is mixing with natural rubber (NR), which keeps the biodegradability of PLA. To increase the PLA toughness with NR, three main criteria must be met: small NR droplets (1-5 $\mu \mathrm{m})$, homogeneous distribution of the NR, and good interfacial adhesion [1-5]. Another way to increase toughness of PLA is the dynamic vulcanization [6-8]. In this method crosslinking agent was added to PLA/NR blend during the mixing which results in small vulcanized NR droplets dispersed in PLA. In our study we investigated the effect of the natural rubber content and dynamic vulcanization on the properties of PLA and analyzing the connection between the structure and properties were analyzed.

\section{Experimental}

For the tests Natureworks 3052D Poly(lactic acid) and bulk natural rubber with a Mooney viscosity ML(1+4) $=60-70$ were used. Before blend preparations, the PLA was dried for 4 hours. Brabender Plastograph internal mixer was used for making different PLA/NR blends with 5, 10, 20 and $30 \mathrm{wt} \%$ NR content and also vulcanized versions were made with 2 phr sulfur, 5 phr zink-oxide, 2 phr stearin acid and 1,5 phr CBS (N-Cyclohexil-2-benztiazil-sulfenamid). The mixing temperature was $190^{\circ} \mathrm{C}$ and mixing time was $5+5$ minutes. The specimens were prepared by hot pressing at $190^{\circ} \mathrm{C}$ for 5 minutes by applying 15 bars. Tensile, flexural and Charpy impact tests, were carried out to analyze the effect of NR on the mechanical properties of PLA. Also scanning electron microscopy (SEM) and differential scanning calorimetry (DSC) were performed to examine the morphology and crystallinity.

\section{Results and discussion}

Our study begun by examining of the toughening effect of NR on the PLA. Unnotched and notched Charpy impact tests were carried out. It was found that the optimum natural rubber concentration is about 5-10 wt $\%$. It can be seen in Fig. 1. that the unnotched impact strength increased from 
$20.5 \mathrm{~kJ} / \mathrm{m}^{2}$ to $61.3 \mathrm{~kJ} / \mathrm{m}^{2}$ with $10 \mathrm{wt} \% \mathrm{NR}$. In the case of notched Charpy tests the best results also could be reached by adding $10 \mathrm{wt} \% \mathrm{NR}$ to PLA. The unnotched impact strength increased from $3.8 \mathrm{~kJ} / \mathrm{m}^{2}$ to $9.3 \mathrm{~kJ} / \mathrm{m}^{2}$. Over $10 \mathrm{wt} \% \mathrm{NR}$ the impact energy decreased, also the dynamically vulcanized blends have performed worse.

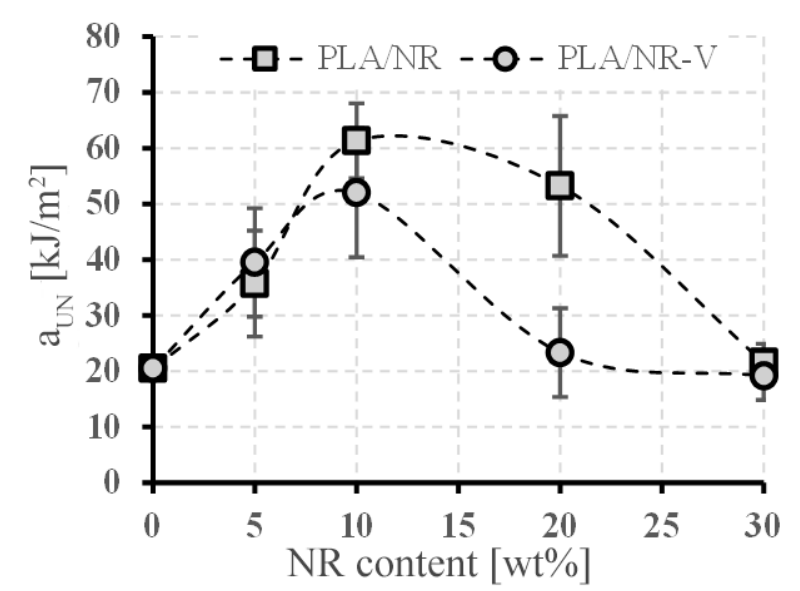

a

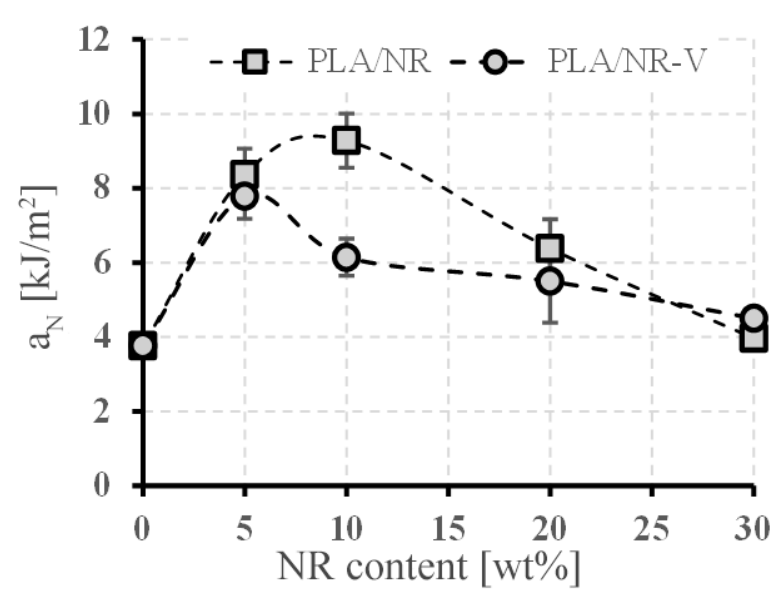

b

Figure 1. Charpy impact strength of PLA/NR blends: unnotched (a), notched (b)

The blends structure were analyzed with scanning electron microscopy (SEM) and the result can be seen in Fig. 2. The size of NR droplets increased with increasing rubber content and the dispersion were found to be better at lower contents because at higher NR content the shear rate of the internal mixer was not enough to disperse the NR correctly in the PLA matrix. Connected to the Charpy measurements, it was found that the impact strength were significantly affected by the NR droplets size and distribution. The critical value in diameter was about $5 \mu \mathrm{m}$, above this value negative effect was observed. It is visible that the level of adhesion between the PLA and NR is quiet low, surface treatment needed for in further research.
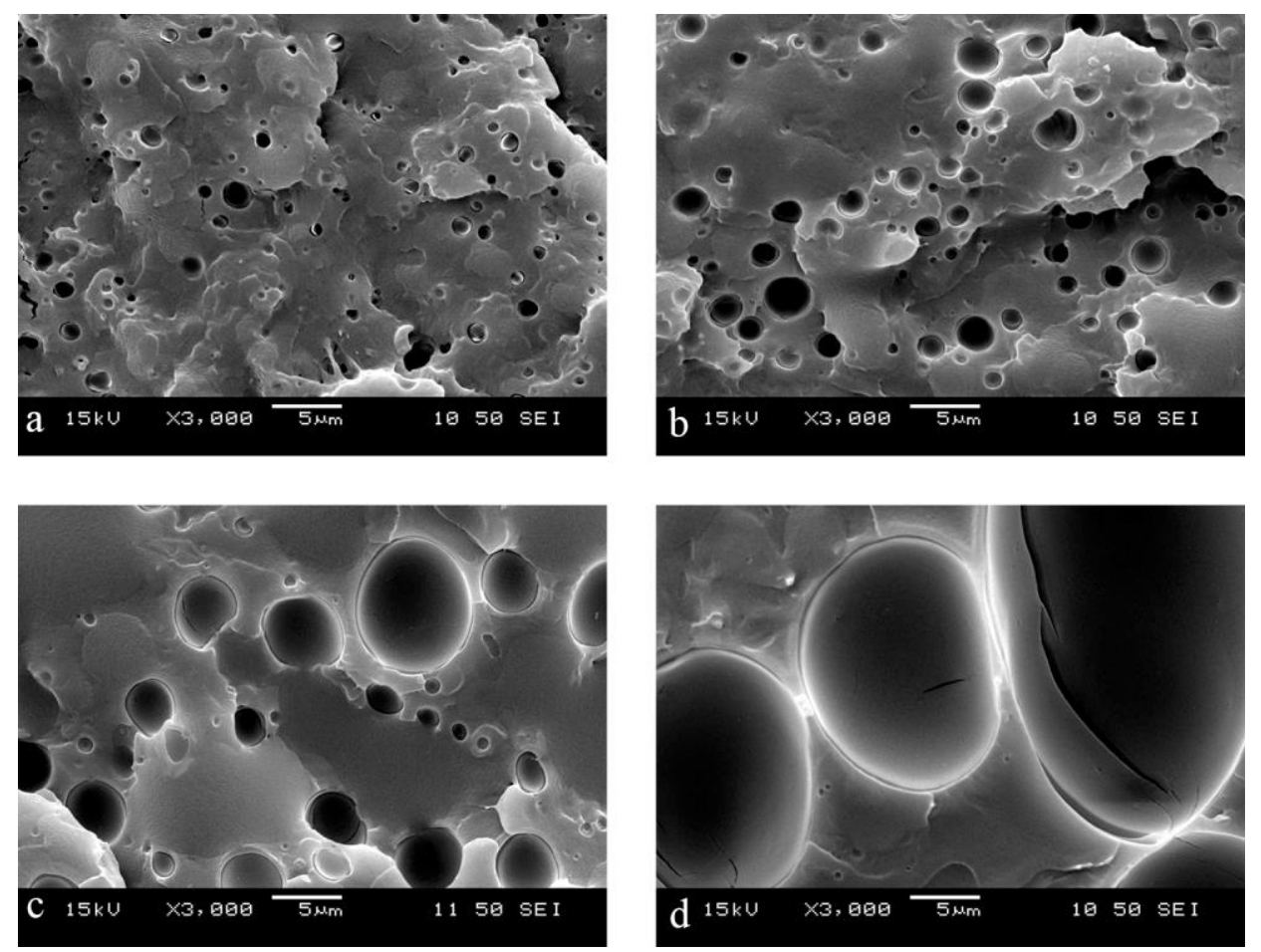

Figure 2. SEM images of PLA/NR blends: 5 wt $\%$ (a), $10 \mathrm{wt} \%$ (b), $20 \mathrm{wt} \%$ (c), $30 \mathrm{wt} \%$ (d) 
Tensile and flexural properties were also investigated in a function of NR content. By adding $10 \mathrm{wt} \%$ of NR the impact strength increased up to $61.3 \mathrm{~kJ} / \mathrm{m}^{2}$ while both the tensile strength and modulus decreased linearly to $42 \mathrm{MPa}$ and 1,8 GPa (Fig. 3.), but it is quite enough for average applications made by polypropylene (PP) or acrylonitrile-butadiene-styrene (ABS). The properties of vulcanized blends decreased more than the non-vulcanized. The NR had significant effect on the elongation at brake over $20 \mathrm{wt} \%(12 \%)$ and it is increased up to 55\% with $30 \% \mathrm{NR}$. In the case of vulcanized compounds no major changes were seen (Fig. 4.).

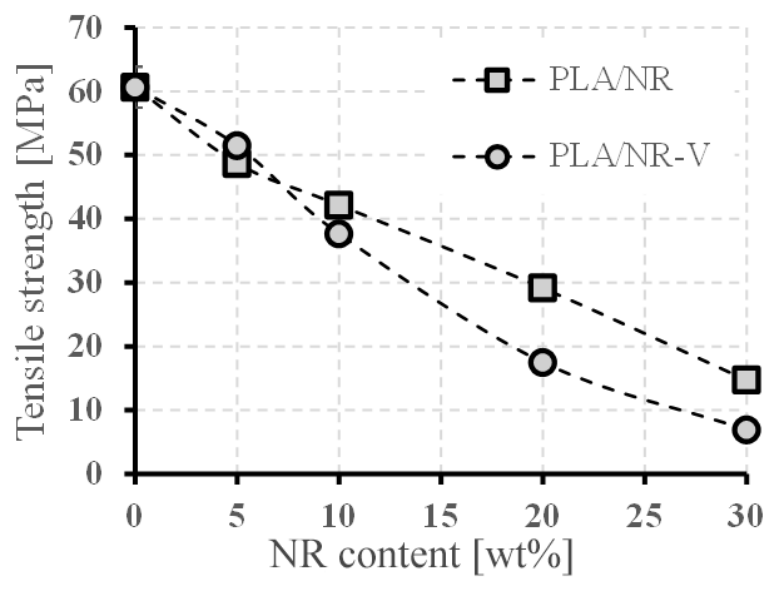

a

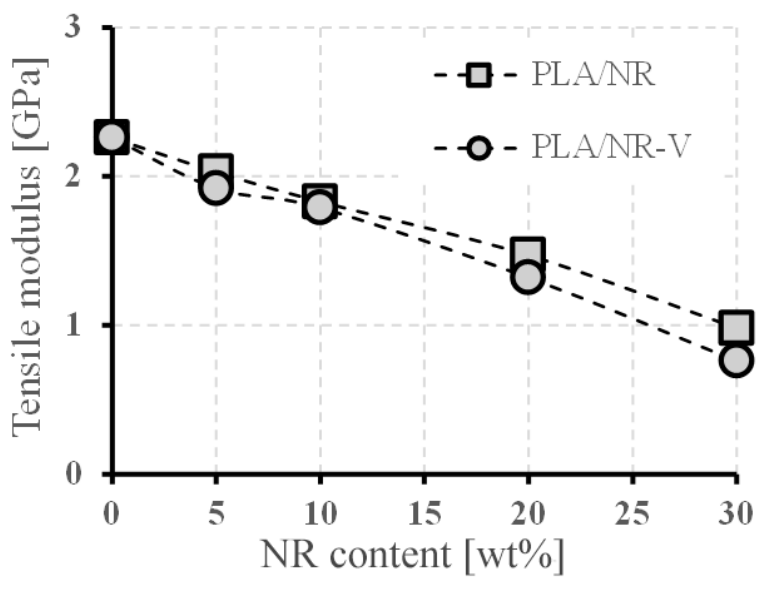

b

Figure 3. Tensile properties of PLA/NR blends: tensile strength (a), tensile modulus (b)

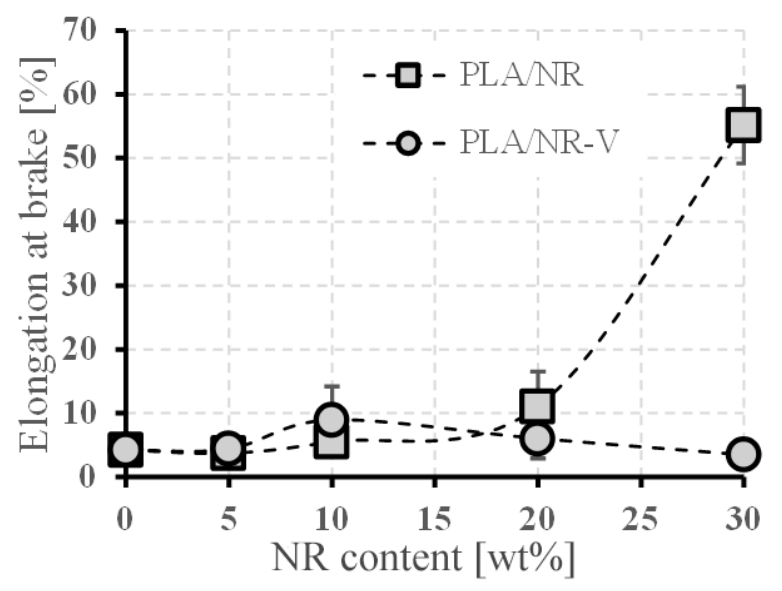

a

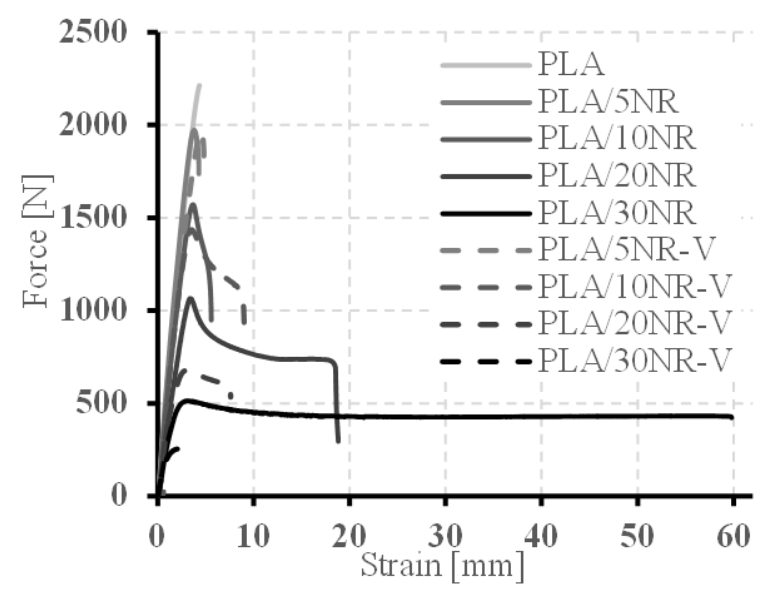

b

Figure 4. PLA/NR blends elongation at brake (a), and tensile characteristics (b)

The flexural properties of the blends were also measured, the results can be seen in Fig 5. It shows the same tendency as for the tensile properties. The flexural strength and modulus linearly decreased with increasing NR content. The optimum NC content was found - from the point of view of impact strength - when the flexural strength is $70 \%$ of the reference which is $67 \mathrm{MPa}$, and the modulus is $85 \%$ of the reference. Also at higher NR contents the vulcanized blends had worse results. 


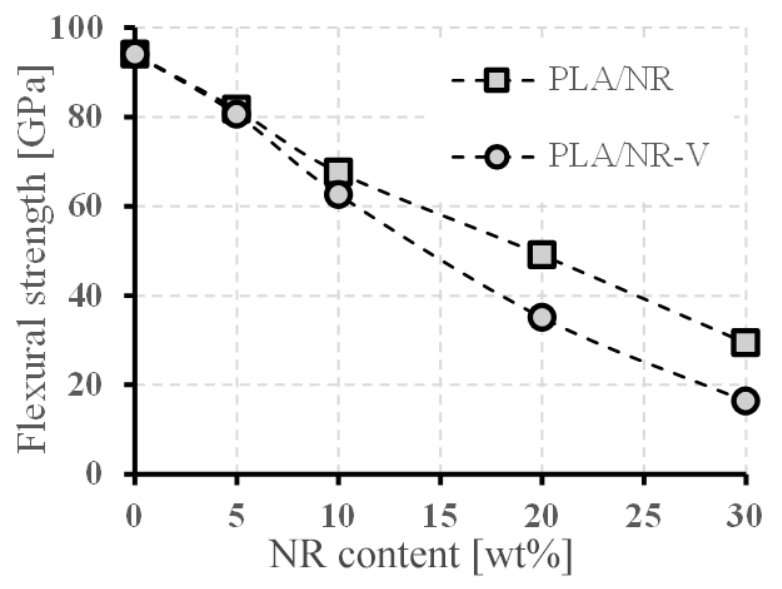

a

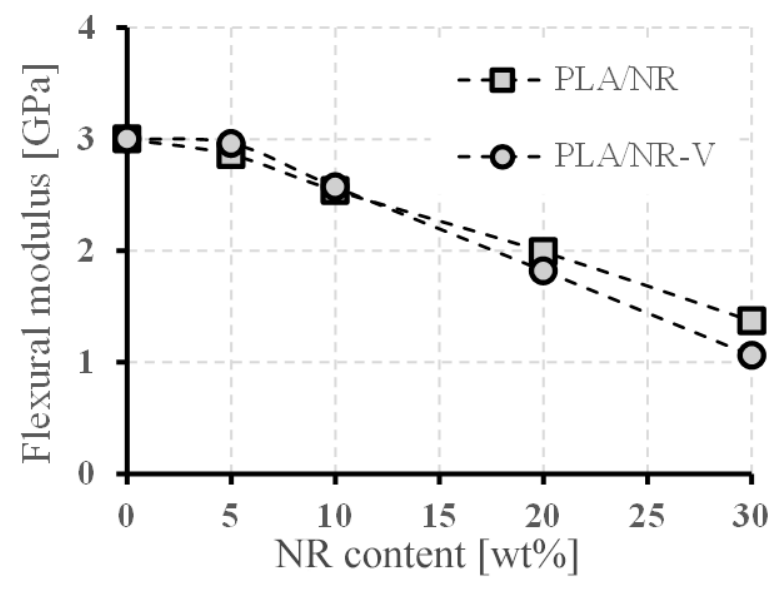

b

Figure 5. Flexural properties of PLA/NR blends: flexural strength (a), flexural modulus (b)

The crystallinity $\left(\mathrm{X}_{\mathrm{c}}\right)$ and the glass transition temperature $\left(\mathrm{T}_{\mathrm{g}}\right)$ were analyzed with differential scanning calorimetry (DSC) from the first heating scan $\left(2{ }^{\circ} \mathrm{C} / \mathrm{min} 0-200^{\circ} \mathrm{C}\right)$. It was found that the natural rubber had no significant effect on both the crystallinity and glass transition temperature (Table 1. and Fig 6).

\begin{tabular}{|l|r|r|}
\hline & $\operatorname{Tg}\left[{ }^{\circ} \mathrm{C}\right]$ & \multicolumn{1}{|c|}{ Xc [\%] } \\
\hline PLA & 58.9 & 2.7 \\
\hline PLA/5NR & 57.5 & 5.4 \\
\hline PLA/10NR & 59.9 & 7.6 \\
\hline PLA/20NR & 62.1 & 4.2 \\
\hline PLA/30NR & 58.2 & 2.4 \\
\hline PLA/5NR-V & 60.2 & 3.6 \\
\hline PLA/10NR-V & 61.0 & 3.7 \\
\hline PLA/20NR-V & 55.9 & 3.4 \\
\hline PLA/30NR-V & 55.1 & 8.5 \\
\hline
\end{tabular}

Table 1. DSC results

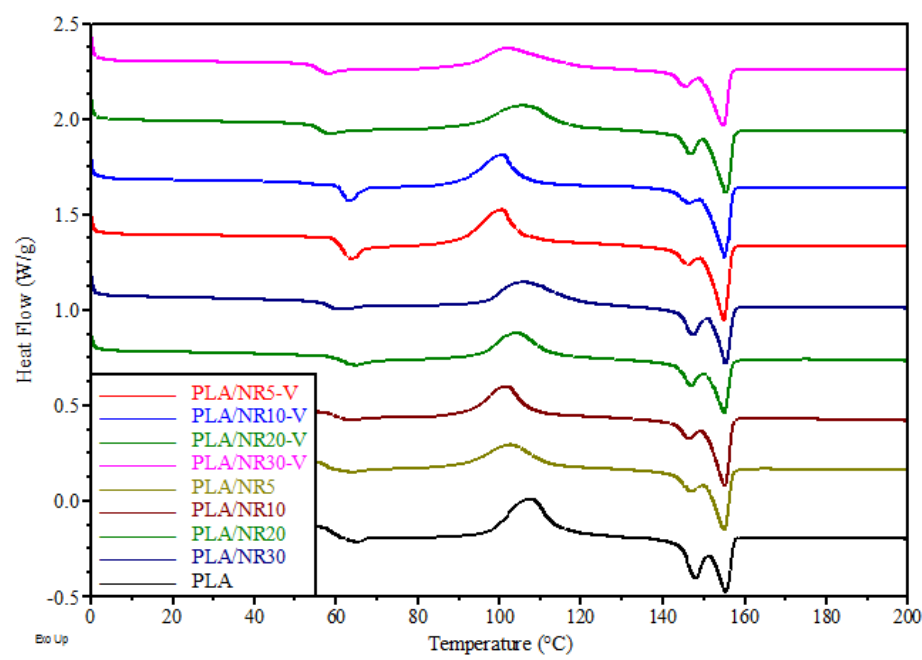

Figure 5. DSC first heating scans

\section{Summary}

In our work the effect of the natural rubber (NR) content and dynamic vulcanization on the properties of Poly(lactic acid) (PLA) were analyzed and the connection between structure and properties was examined. The measurements results showed that the optimum NR content is about $10 \mathrm{wt} \%$ and by adding this amount to PLA, three time higher Charpy impact strength was found compared to neat PLA at the cost of maximum $30 \%$ decrease in both tensile and flexural strength and moduli. Scanning electron microscopy showed that at lower NR contents the dispersion was better and the NR droplets size was under $5 \mu \mathrm{m}$, however over $10 \mathrm{wt} \%$ bigger NR doplets were found which caused significant decrease in the impact strength. DSC measurements were also carried out but no significant effect was found.

\section{Acknowledgements}

This paper was supported by the János Bolyai Research Scholarship of the Hungarian Academy of Sciences. This publication was supported by the Italian-Hungarian and the Mexican-Hungarian 
bilateral agreement of the Hungarian Academy of Sciences. This work was supported by the Hungarian Scientific Research Fund (OTKA K105257). This work is connected to the scientific program of the "Development of quality-oriented and harmonized $\mathrm{R}+\mathrm{D}+\mathrm{I}$ strategy and functional model at BME" project. This project is supported by the New Széchenyi Plan (Project ID: TÁMOP4.2.1/B-09/1/KMR-2010-0002). The work reported in this paper has been developed in the framework of the project "Talent care and cultivation in the scientific workshops of BME" project. This project is supported by the grant TÁMOP - 4.2.2.B-10/1-2010-0009.

\section{References}

[1] D. Garlotta.: A Literature review of poly(lactic acid). Journal of Polymers and the Environment, 9, 63-84 (2001).

[2] R. Auras, L-T. Lim, S. E. M. Selke, H. Tsuji: Poly(lactic acid) synthesis, structures, properties, processing, and applications. John Wiley \& Sons Inc. Hoboken, New Jersey (2010).

[3] N. Bitinis, R. Verjdejo, P. Cassagnau, M. A. Lopez-Manchado: Structure and properties of polylactide/natural rubber blends. Materials Chemistry and Physics, 129, 823-831 (2011).

[4] K. Pongtanayut, C. Thongpin, O. Santawitee: The effect of rubber on morphology, thermal properties and mechanical properties of PLA/NR and PLA/ENR blends. Energy Procedia, 34, 888-897 (2013).

[5] C. Xu, D. Yuan, L. Fu, Y. Chen: Physical blend of PLA/NR with co-continuous phase structure: Preparation, rheology prperty mechanical properties and morphology. Polymer Testing 37, 94101 (2014).

[6] Y. Chen, D. Yuan, C. Xu: Dynamically Vulcanized Biobased Polylactide/Natural Rubber Blend Material with Continuous Cross-Linked Rubber Phase. ACS Appl Mater Interfaces, 6, 38113816 (2014).

[7] D. Yuan, C. Xu, Z. Chen, Y. Chen: Crosslinked bicontinuous biobased polylactide/natural rubber materials: Super toughness, "net-like"-structure of NR phase and excellent interfacial adhesion. Polymer Testing, 38, 73-80 (2014).

[8] D. Yuan, K Chen, C. Xu, Z. Chen, Y. Chen: Crosslinked bicontinuous biobased PLA/NR blends via dynamic vulcanization using different curing systems. Carbohydrate Polymers, 113, 438445 (2014). 